\title{
The Impact of Male Physical Attractiveness in Predicting Wives' Marital Satisfaction
}

I.Y.Abdallah ${ }^{1}$, H.M.El Hady ${ }^{2}$ and H.A.Abdou ${ }^{1}$

Dermatology \& Andrology Dept., Faculty of Medicine, Benha Univ., Benha, Egypt

E-Mail:Heba@gmail.com

\begin{abstract}
Physical qualities assumes a significant part in deciding allure. This examination expects to assess the effect of male physical engaging quality in anticipating spouses' conjugal fulfillment. The current examination was led on 350 female members. The greater part of them were 20-39 years of age $(79.4 \%)$. The vast majority of members $(84.2 \%)$ had a moderate to serious extent of training. Among member (56.0\%) ladies were utilized. There were $46 \%$ members who affirmed that light aroma is the favored sort of scent in their significant other's body as spouse's smell may importantly affect ladies' conjugal fulfillment. $66.6 \%$ of members concurred with the announcement saying that physical engaging quality is a marker for physical wellbeing. Among members, $61.4 \%$ ladies discover light earthy colored skin of men is the most alluring skin shading. there was a disavowal by $56.9 \%$ members that there is significant connection between genuinely appealing spouse and sound kin kids. About the significance of noticeable muscles as an alluring physical sign for ladies, $56.9 \%$ members said that conspicuous muscles in men are not appealing for them. Overweight was chosen by $54.6 \%$ ladies to turn into the huge issue that may confront them with their spouses' bodies. Physical man's engaging quality has a connection to his ripeness was chosen by $59.4 \%$ ladies. $68.2 \%$ of ladies indicated that their sexual want toward their spouses is middle. Our examination demonstrated that the spouse's physical appeal greatly affects female sexual reaction.
\end{abstract}

Keywords: Physical, Attractiveness, Marital, Satisfaction, sexual desire.

\section{Introduction}

Do ladies esteem physical allure in a mate more than men? Researchers in various controls accept that they do, yet research utilizing speed-dating ideal models recommends that guys and females are similarly affected by physical appeal while picking potential mates [1].

Transformative analysts were among the first to recommend that people contrast in their inclination for genuinely alluring mates. All through human transformative history, male regenerative achievement ought to have been dictated by men's capacity to get female mates who were profoundly rich. Since youth and physical appearance (e.g., huge eyes, smooth skin, full lips-characteristics that are seen as profoundly appealing in the present society) are solid markers of female fruitfulness, men who were pulled in to and ready to acquire truly alluring female mates probably created more enduring posterity than did men who didn't like and search out genuinely appealing female mates [2].

Given that physical engaging quality was not a solid marker of male richness, interestingly, ladies would not have profited as much as men from mating with alluring accomplices and in this way ought not have developed as solid an inclination for truly appealing accomplices [3].

As Buss put it, "male fruitfulness, to the extent that it is esteemed by females, is less steeply age-reviewed from pubescence on than is female ripeness and subsequently can't be surveyed as precisely from physical appearance." Thus, it follows that people would have developed with the end goal that accomplice physical engaging quality is more integral to men's relationship inclinations and assessments than it is to ladies' [4].
In many examinations, the two accomplices' physical engaging quality was unbiasedly appraised at pattern and the two accomplices announced their conjugal fulfillment up to multiple times over the initial four years of marriage. While spouses were more fulfilled toward the start of the marriage and stayed more fulfilled throughout the following four years to the degree that they had an appealing wife, wives were no pretty much fulfilled at first or over the course of the following four years to the degree that they had an alluring husband [5].

Above all, an immediate test showed that accomplice physical appeal assumed a bigger part in foreseeing spouses' fulfillment than anticipating wives' fulfillment. These discoveries fortify help for the possibility that sexual orientation contrasts in selfdetailed inclinations for physical engaging quality do have suggestions for long haul relationship results [6].

This investigation intends to assess the effect of male physical allure in anticipating spouses' conjugal fulfillment.

\section{Patients and methods}

The current examination is a cross sectional investigation. The members will be hitched ladies in standard sexual relationship with their spouses.

In the wake of taking the endorsement of Ethical Committee and Dermatology and Andrology division in Banha University, the examination will continue as follows: the apparatus of the examination will be a selfreport poll planned by the specialists, the point of the investigation and subtleties of survey will be disclosed to the ladies before taking their educated assent.

Members of the investigation will be ladies going to the outpatient center of Banha University Hospital in the 4 months time frame following beginning the examination. 
To guarantee that all assembled data will be kept private and the subject will be mysterious, every poll will be turned in an open envelope and subsequent to filling it, the subject will seal the envelope and put it in a container containing other fixed envelopes.

\section{Inclusion criteria}

Married women in regular sexual relationship with their husbands.

\section{Exclusion criteria}

- Unmarried women.

- Presence of any medical conditions affecting female sexuality and their judgment.

- If husband is absent or has sexual dysfunction.

\section{Statistical analysis}

The results will be tabulated and statistically analyzed using the appropriate statistical methods. Qualitative data will be described using number and percent. Quantitative data will be described using mean and standard deviation.

\section{Results}

The most common age group in participants was 30-39 years that contains 158 women (45.1\%). Employed participants were 196 women (56.0\%). Among participants, 281 women $(80.2 \%)$ had a university degree and 184 women $(52.6 \%)$ were living in a city Table (1).

Table (1) Demographic data among studied group.

\begin{tabular}{|c|c|c|}
\hline \multirow[t]{2}{*}{ Variable } & \multicolumn{2}{|c|}{$\begin{array}{l}\text { Studied group } \\
(\mathrm{n}=350)\end{array}$} \\
\hline & $\mathbf{n}$ & $\%$ \\
\hline \multicolumn{3}{|l|}{ Age: (years) } \\
\hline$<20$ years & 26 & 7.4 \\
\hline $20-29$ & 120 & 34.3 \\
\hline 30-39 & 158 & 45.1 \\
\hline $40-49$ & 46 & 13.1 \\
\hline \multicolumn{3}{|l|}{ Educational level } \\
\hline Read and write & 55 & 15.7 \\
\hline Secondary school & 14 & 4.0 \\
\hline University graduate & 281 & 80.3 \\
\hline \multicolumn{3}{|l|}{ Place of residence } \\
\hline Village & 166 & 47.4 \\
\hline City & 184 & 52.6 \\
\hline \multicolumn{3}{|l|}{ Occupation } \\
\hline Student & 20 & 5.7 \\
\hline Employed & 196 & 56.0 \\
\hline No job & 134 & 38.3 \\
\hline \multicolumn{3}{|l|}{ Duration of marriage } \\
\hline$>5$ years & 109 & 31.1 \\
\hline 5-15 years & 181 & 51.7 \\
\hline $15-30$ years & 60 & 17.1 \\
\hline
\end{tabular}

In this study, 161 women $(46.0 \%)$ preferred light fragrances as a kind of odor in their husband's body. In addition, 233 women $(66.6 \%)$ confirmed that physical attractiveness of their husbands is considered a mark of their physical health. Results show that 215 women

(61.4\%) preferred light brown skin color in their husbands. Among 199 women, 56.9\% disagreed that physical attractiveness of their husbands is important for healthy children.

Among 199 studied women, 56.9\% disagreed that prominent muscles make a man more attractive. Among 191 women, 54.6\% confirmed that over-weight is the big problem may face them in their husband's body. Results show that 208 women $(59.4 \%)$ believe that physical man's attractiveness has a relation to his fertility. 239 women $(68.2 \%)$ of all studied women said that their sexual desire for their husbands is intermediate. Among $290,82.9 \%$ studied women disagreed that physically attractive body husbands affect their satisfaction in marriage.

Among 228 women, $65.1 \%$ agreed the presence of the effect of body hygiene of their husbands on their satisfaction. Results show that 293 women (83.7\%) agreed that their perception of attractiveness of their husband's body changes around menstrual cycle and 159 women $(43.7 \%)$ said that they preferred their husbands with strong fragrances. In response to question of the period that women can stand without having sexual activity with their husbands 150 women $(42.9 \%)$ said for few weeks Table (2).

Table (2) Husbands' attractiveness and sexual activity in the studied group. 


\begin{tabular}{|c|c|c|}
\hline \multirow[t]{2}{*}{ Variable } & \multicolumn{2}{|c|}{$\begin{array}{c}\text { Studied group } \\
(\mathbf{n}=\mathbf{3 5 0})\end{array}$} \\
\hline & $\mathrm{n}$ & $\%$ \\
\hline \multicolumn{3}{|c|}{ kind of odor preferred in husband's body } \\
\hline Strong fragrances & 82 & 23.4 \\
\hline Light fragrances & 161 & 46.0 \\
\hline Natural skin odor of your husband & 107 & 30.6 \\
\hline \multicolumn{3}{|c|}{ Physical attractiveness as a mark for physical health } \\
\hline Yes & 233 & 66.6 \\
\hline No & 117 & 33.4 \\
\hline \multicolumn{3}{|l|}{ Preferred color of man's skin } \\
\hline Man who has dark skin & 100 & 28.6 \\
\hline Man who has light brown skin & 215 & 61.4 \\
\hline Man who has white skin & 35 & 10.0 \\
\hline \multicolumn{3}{|c|}{ Choosing a physically attractive husband is important for healthy children } \\
\hline Yes, I believe in this & 151 & 43.1 \\
\hline No, there is no relation & 199 & 56.9 \\
\hline \multicolumn{3}{|c|}{ Prominent muscles make a man more attractive } \\
\hline Yes & 151 & 43.1 \\
\hline No & 199 & 56.9 \\
\hline \multicolumn{3}{|c|}{ What a big problem may face you in husband's body } \\
\hline Over weight & 191 & 54.6 \\
\hline Bad body odor & 117 & 33.4 \\
\hline Smooth skin & 42 & 12.0 \\
\hline \multicolumn{3}{|c|}{ Physical man's attractiveness has a relation to his fertility } \\
\hline Yes & 208 & 59.4 \\
\hline No & 142 & 40.6 \\
\hline \multicolumn{3}{|c|}{ Level of your sexual desire toward your husband } \\
\hline Low & 24 & 6.9 \\
\hline Intermediate & 239 & 68.2 \\
\hline High & 87 & 24.9 \\
\hline \multicolumn{3}{|c|}{ A physically attractive body affects satisfaction in marriage } \\
\hline Yes & 60 & 17.1 \\
\hline No & 290 & 82.9 \\
\hline \multicolumn{3}{|l|}{ Body hygiene affects your satisfaction } \\
\hline Agree & 228 & 65.1 \\
\hline Disagree & 122 & 34.9 \\
\hline \multicolumn{3}{|c|}{ Does your perception of attractiveness of your husband's body change around menstrual cycle } \\
\hline Yes & Yes & Yes \\
\hline No & No & No \\
\hline
\end{tabular}

\section{Discussion}

The current investigation was directed on 350 female members. A large portion of them were 20-39 years of age $(79.4 \%)$ which implies that the vast majority of the members were in the time of solid sexual action. A large portion of members (84.2\%) had a moderate to serious extent of instruction. Among member $(56.0 \%)$ ladies were utilized. This implies the outcomes were moderately precise and ignorant people were rejected to let members fill the poll without anyone else to guarantee protection.

Among the members 161 (46\%) ladies affirm that light aroma is the favored sort of smell in their significant other's body. Making the outcomes a stride further-the examination demonstrated that ladies esteemed olfactory prompts altogether more than men in mate decision, and this was expanded with expanded ladies' training and upscale spots. An investigation by Mehmet and Croy [7] affirmed that men's smell gives a wellspring of solace in existing connections and encourages recognizing a solid mate, upgrades sexual encounters, which are indicators of relationship life span and mate determination, and a similar report demonstrated that $50.4 \%$ of members lean toward botanical aromas for men which will in general be light and useful for daytime

At the point when members were inquired as to whether physical engaging quality is an imprint for physical wellbeing, 233 (66.6\%) members concurred with that. In a past report contrasting appealing and genuinely sound grown-up men versus less alluring and truly solid ones, Benz et al [8] has detailed that no relationship was found between men's physical engaging quality and wellbeing in grown-up men. Our outcomes are not coordinating with this examination and this might be because of absence of logical information that demonstrates that not all truly alluring people are sound ones or the other way around, even in exceptionally taught ladies.

In the current examination, $215(61.4 \%)$ ladies discover light earthy colored skin of men is the most appealing skin shading. Skin shading is one of the first highlights that ladies notice in quite a while and, 
subsequently, it assumes a huge part in the mate choice cycle just as in the evaluation of allure of others. In any case, practically all advanced examination indicating an inclination for lighter skin tone (especially in male) was led inside populaces of moderately fair complexion shading, most females (63\%) favored skin conditions that were either normal or somewhat lighter than the normal [9]. In our investigation, we found that answers were variable between members since skin shading speaks to individual inclination and is associated with social ceremonies and imagery, which differ among ladies. Skin shading impacts human conduct and differs as indicated by ladies' inclination, so human shading and its consequences for mate decision and rivalry is variable among ladies' way of life [10].

In the current work 199 member ladies (56.9\%) accept that there is no significant connection between genuinely appealing spouse and sound kin youngsters. This outcome might be found since ladies were picking their mate by target models and psyche decision. Physical appeal has been related with mating conduct, however its function in regenerative accomplishment of people has gotten little consideration .In one examination, Jokela [11] it was discovered that physical allure might be related with conceptive achievement in people living in industrialized contraries, these affiliations were somewhat yet not totally represented by appealing members' expanded marriage likelihood, as in men. There was an edge impact with the goal that men in the most minimal appeal quartile had $13 \%$ less kids than other people who didn't contrast from one another in the normal number of youngsters.

About the significance of noticeable muscles as an alluring physical sign for ladies, 199 members (56.9\%) said that unmistakable muscles in men are not appealing for them. This outcome isn't coordinating with the way that muscles are a wellness pointer and a solid physical make-up would give heritable and direct advantages to females from a familial perspective. It is enticing to extrapolate that the more muscles a male has, the more alluring he will be to the other gender [12]. In all actuality, conspicuous muscles don't assume any function in human mating decision since it is a more mind boggling decision. In an examination by Frederick and Haselton [13], it was discovered that not all ladies would have the option to draw in long haul contributed guys who could pass on great wellness prompts, thus there is a compromise between picking guys who have great wellness pointers and the individuals who will be better long haul accomplices and put resources into family life. All things considered, for momentary connections, or when the male commitment is just hereditary, do ladies will in general favor more solid guys, yet for long haul connections it relies upon strong state of men as well as other multi-factors associated with their decision.

In our investigation $191(54.6 \%)$ ladies said that the enormous issue that may confront them with their spouses' bodies is overweight. At the point when a lady began dating, her accomplice ordinarily had fit body, years after the fact in her marriage, he puts on more weight and gets hefty, so she can't recapture that sentiment of fascination in him and she normally acknowledge that weight gain in a marriage is a piece of life [14]. This is predictable with the finding of Evers [15] that expansion of weight record reflects lower assessed every day level of physical action and great sexual conduct, which influence spouse's conjugal status fulfillment.

The seventh inquiry was about if physical man's allure has a connection to his ripeness, 208 (59.4\%) members addressed yes. These outcomes were not coordinating to an examination Peters and Rhodes [16] which indicated no noteworthy relationships between's semen quality boundaries and appeal or alluring attributes. Albeit male physical allure may flag parts of mate quality, results recommend no connection between physical appeal and male richness. So aftereffects of our examination might be because of wrong convictions and low logical information.

The current investigation indicated that sexual want in spouses toward their husbands is moderate in 239 $(68.2 \%)$ of members. It's regular shrewdness that ladies place more an incentive on passionate association in their sexual life. Yet, ladies additionally have all the earmarks of being vigorously affected by social and social factors also. Sexual want in ladies is incredibly delicate to condition and setting. One examination about sexual want demonstrated that, there are no proportions of want, as such, with the current choices including proportions of sexual perceptions [17].

In our examination, We interrogated regarding impact of spouse's physical body engaging quality on conjugal fulfillment, we found that 290 (82.9\%) of partaking ladies affirm that there was no impact. This outcome might be because of probability of ladies' acknowledgment of her spouses' weight gain as a reality in conjugal life thus they become adjusted on this reality. This is as opposed to one investigation about this issue in USA that found that men's body would anticipate expanded sexual recurrence and accordingly expanded sexual and conjugal fulfillment for ladies, particularly in working ladies (55\%) than in non-working ladies [17].

The current examination indicated that terrible body cleanliness influenced ladies' conjugal fulfillment in $228(65.1 \%)$ of ladies. This is steady with another investigation [18], which indicated that conjugal trouble and strife are connected to poor physical cleanliness and the nature of connections is connected with men's physical wellbeing cleanliness. The outcome is predictable with presence of mind of humankind as great cleanliness of man is a significant indication of his positive outlook of his life.

\section{Conclusion}

It was found that participants had high numbers of wrong beliefs about the physical attractiveness as a 
marker for physical health. Participants had good numbers of right beliefs about the relationship between physically attractive husband and healthy sibling children, husband's overweight, husband's physical body attractiveness and its effect on their marital satisfaction, body hygiene importance and women's menstrual cycle effect. We also found that participants had variable numbers of beliefs about the period that participating woman can stand without having sexual activity, their sexual desire toward their husbands, the prominent muscles effect in men, the skin color of men.

\section{References}

[1] P.W.Eastwick, L.A.Neff, Do ideal partner preferences predict divorce? A tale of two metrics," Soc. Psychol. Personal. Sci, Vol.3 (6), PP. 667-674, 2012.

[2] K.Grammer , K.L.Sainani. Innate attractions," Nature, Vol.526, no. 7572, PP. S11-S11, 2015.

[3] N.AVashi. Objective aspects of beauty," in Beauty and Body Dysmorphic Disorder, Springer.vol. 2015(1), PP. 17-43, 2015.

[4] D.M.Buss, D.P.Schmitt. Sexual strategies theory: an evolutionary perspective on human mating.," Psychol. Rev, Vol.100,(2), p. 204, 1993.

[5] G.J.O.Fletcher, J.A.Simpson, L.Campbell. Pairbonding, romantic love, and evolution: The curious case of Homo sapiens," Perspect. Psychol. Sci, Vol.10(1), PP. 20-36, 2015.

[6] J.K.McNulty, C.A.Wenner, T.D.Fisher. Longitudinal associations among relationship satisfaction, sexual satisfaction, and frequency of sex in early marriage," Arch. Sex. Behav., vol. 45(1), PP. 85-97, 2016.

[7] M. K.Mahmut , I. Croy, "The role of body odors and olfactory ability in the initiation, maintenance and breakdown of romantic relationships-A review," Physiol. Behav, Vol.207, PP. 179-184, 2019.
[8] J. Benz, C. Blakey, C. C. Oppenheimer, H. Scherer, and W. T. Robinson, "The Healthy People Initiative: Understanding the User's Perspective," J. Public Heal. Manag. Pract, Vol. 19(2), PP. 103109, 2013.

[9] C.A.Thorstenson. The social psychophysics of human face color: review and recommendations," Soc. Cogn, Vol.36(2), PP. 247-273, 2018.

[10] A.J.Elliot, M.A.Maier. Color psychology: Effects of perceiving color on psychological functioning in humans," Annu. Rev. Psychol, Vol.65, PP. 95120, 2014.

[11] M. Jokela. Physical attractiveness and reproductive success in humans: evidence from the late 20th century United States," Evol. Hum. Behav, Vol.30(5), PP. 342-350, 2009.

[12] J.M.Tybur, A.D.Bryan, A.E.C.Hooper. An evolutionary perspective on health psychology: New approaches and applications," Evol. Psychol, Vol.10(5), p. 147470491201000500, 2012.

[13]D.A.Frederick M.G.Haselton. Why is muscularity sexy? Tests of the fitness indicator hypothesis," Personal. Soc. Psychol. Bull., vol. 33(8), PP. 1167-1183, 2007.

[14] J.H.Carmalt, J.Cawley, K.Joyner, J.Sobal. Body weight and matching with a physically attractive romantic partner,' J. Marriage Fam, Vol.70(5), PP. 1287-1296, 2008.

[15] S. Evers, "Economic and social factors associated with obesity in adult Canadians," Nutr. Res, vol. 7(1), PP. 3-13, 1987.

[16] M. Peters, G. Rhodes, L.W.Simmons. Does attractiveness in men provide clues to semen quality?," J. Evol. Biol, Vol.21(2), PP. 572-579, 2008.

[17] J.G.Beck. Hypoactive sexual desire disorder: An overview.," J. Consult. Clin. Psychol, Vol. 63(6), p. 919, 1995.

[18] M.A.Whisman , L.A.Uebelacker. Comorbidity of relationship distress and mental and physical health problems, Vol.19(2), PP. 103-109 2003. 